Bài báo khoa học

\title{
Nghiên cứu cơ sở khoa học xây dựng bộ tiêu chí đánh giá hiệu quả các mô hình kinh tế cấp huyện thích ứng với biến đổi khí hậu vùng Đồng bằng sông Cửu Long
}

\author{
Đặng Ngọc Điệp ${ }^{1 *}$, Nguyễn Văn Thắng², Lê Ngọc Cầu², Lê Văn Quy², Phạm Thị Quỳnh², \\ Phạm Văn S:̃ ${ }^{2}$
}

${ }^{1}$ Bộ Tài nguyên và Môi trường; diepvp.ttcp@gmail.com

${ }^{2}$ Viện Khoa học Khí tượng Thủy văn và Biến đổi khí hậu;

nvthang.62@gmail.com; caukttv@gmail.com; vanquymt@gmail.com; quynhpt0310@gmail.com; phamsymt@gmail.com

* Tác giả liên hệ: diepvp.ttcp@gmail.com; Tel.: +84-904729009

Ban Biên tập nhận bài: 12/8/2020; Ngày phản biện xong: 08/10/2020; Ngày đăng: $25 / 10 / 2020$

Tóm tắt: Đồng bằng sông Cửu Long (ĐBSCL) đã và đang phải chịu sự tác động mạnh mẽ của biến đổi khí hậu BĐKH như nước biển dâng, xâm nhập mặn, xói lở và ngập lụt, đe dọa rất lớn tới sự phát triển nông nghiệp, an ninh lương thực quốc gia và gây ra nhiều thiệt hại tới kinh tế xã hội của vùng. Trong thời gian vừa qua, nhiều mô hình kinh tế cấp huyện thích ứng với $\mathrm{BĐKH}$ đã được hình thành và triển khai tại một số khu vực trong vùng ĐBSCL như mô hình lúa-cá, mô hình trồng cỏ voi nuôi bò và dê, và từng bước mang lại hiệu quả nhất định về mặt kinh tế. Để thực hiện tiến hành triển khai, nhân rộng các mô hình kinh tế ra các vùng khác, cần phải có những đánh giá chuyên sâu về mặt hiệu quả kinh tế cũng như sự thích ứng với biển đổi khí hậu. Hiện nay, đã có các bộ tiều chí đánh giá riêng lẻ hiệu quả kinh tế, hoặc hiệu quả thích ứng với $\mathrm{BĐKH}$, chứ chưa có bộ tiêu chí đánh giá tổng hợp cùng lúc cả về kinh tế lẫn thích ứng với $\mathrm{BĐKH}$ của các mô hình kinh tế ở quy mô cấp huyện và xã. Vì thế, mục tiêu của nghiên cứu này là xây dựng bộ tiêu chí đánh giá hiệu quả các mô hình kinh tế cấp huyện thích ứng với $\mathrm{B} Đ K H$ dựa trên phương pháp kế thừa, phân tích hệ thống, điều tra khảo sát, thảo luận nhóm tập trung, phương pháp chuyên gia Delphi và phỏng vấn chuyên gia, cán bộ và các hộ dân triển khai mô hình. Bộ tiêu chí được xây dựng với 6 nhóm tiêu chí chính và 25 chỉ số tương ứng phản ánh các khía cạnh khác nhau của mô hình kinh tế thích ứng với $\mathrm{BĐKH,} \mathrm{ví} \mathrm{dụ} \mathrm{như} \mathrm{khả} \mathrm{năng} \mathrm{thích} \mathrm{ứng} \mathrm{với} \mathrm{BĐKH,} \mathrm{giảm} \mathrm{nhẹ} \mathrm{phát} \mathrm{thải}$ nhà kính, và đảm bảo tính hiệu quả và bền vững đối với môi trường, kinh tế và xã hội.

Từ khóa: Bộ tiêu chí; Mô hình kinh tế; Thích ứng với biến đổi khí hậu.

\section{Mở đầu}

Vùng ĐBSCL được xem như là một trong những đồng bằng chịu tác động nặng nề của biến đổi khí hậu và nước biển dâng. Đặc điểm tự nhiên của vùng ĐBSCL là một vùng châu thổ có địa hình thấp và phẳng-độ cao trung bình so với mực nước biển chỉ vào khoảng 1,0 $1,8 \mathrm{~m}$, diện tích toàn vùng khoảng 4 triệu ha đất tự nhiên, trong đó đất sử dụng cho nông nghiệp là 2,2 triệu ha. Vùng ĐBSCL nằm ở vị trí hạ lưu của sông Mekong, với một hệ thống sông rạch và kênh mương chằng chịt, có đường ven biển dài trên $700 \mathrm{~km}$ [1]. Về mặt kinh tế và xã hội, vùng ĐBSCL là nơi sinh sống của gần 20 triệu người dân, là khu vực sản xuất nông nghiệp và thuỷ sản lớn nhất Việt Nam, đóng góp một sản lượng lương thực và thực phẩm 
đáng kể cho quốc gia và xuất khẩu một phần cho quốc tế [2]. Vùng ĐBSCL có 3 vùng sinh thái chính bao gồm vùng ngập lũ (ngập sâu và kéo dài từ $2-3$ tháng/năm), vùng giữa (vùng phù sa nước ngọt, ngập nông và nhiếm mặn nhẹ), và vùng ven biển (trên 6 tháng bị nhiễm mặn ở các mức độ) [3].

Trong những năm gần đây, trên phạm vi cả nước, các giải pháp, thực hành và mô hình thích ứng với $\mathrm{BĐKH} \mathrm{đã} \mathrm{được} \mathrm{triển} \mathrm{khai} \mathrm{thử} \mathrm{nghiệm} \mathrm{trên} \mathrm{nhiều} \mathrm{quy} \mathrm{mô} \mathrm{và} \mathrm{lĩnh} \mathrm{vực} \mathrm{đa} \mathrm{dạng,}$ khác nhau [4-7]. Trong đó, nổi lên một số mô hình kinh tế có tiềm năng mang lại cả về hiệu quả kinh tế lẫn thích ứng với biến đổi khí hậu trong lĩnh vực nông, lâm nghiệp và kết hợp nuôi trồng thủy sản như mô hình cánh đồng lớn [8], vườm ươm và mô hình lúa cá [4]. Những mô hình này đang được khuyến khích và nhân rộng.

Hiện nay đã có một vài bộ chỉ số đánh giá hiệu quả kinh tế của các mô hình kinh tế thích ứng với biến đổi khí hậu. Chẳng hạn như, Bộ tiêu chí đánh giá mô hình sinh kế thích ứng với BĐKH của tổ chức CARE quốc tế Việt Nam, xây dựng năm 2015 với 5 tiêu chí tương thích thuộc 2 chỉ tiêu chuẩn. Trong đó, 3 tiêu chí gồm Tương thích về kinh tế; thể chế, và văn hóa xã hội thuộc tiêu chuẩn sinh kế bền vững và 2 tiêu chí gồm Tương thích khí hậu và môi trường thuộc tiêu chuẩn thích ứng với $\mathrm{BĐKH}$. Tuy vậy, bộ tiêu chí này còn tồn tại mặt hạn chế bởi tiêu chuẩn 2 là tiêu chuẩn sinh kế thích ứng với $\mathrm{BĐKH}$, nên chỉ tiêu môi trường nên đặt ở Tiêu chuẩn 1 . Ngoài ra, bộ tiêu chí này chưa đánh giá thang điểm cho các chỉ số dựa vào mức độ ưu tiên của địa phương [9]. Bên cạnh đó, Viện KHKTTV \& BĐKH cũng xây dựng bộ chỉ số thích ứng với BĐKH với 4 bộ tiêu chí (chỉ số cấp I), bao gồm Khả năng chống chịu của môi trường tự nhiên; Đánh giá tính dễ bị tổn thương do BĐKH; Giảm nhẹ rủi ro do BĐKH; và Đánh giá hiệu quả các hoạt động thích ứng với BĐKH. Trong đó, mỗi bộ chỉ số (cấp I) lại có các chỉ số cấp II và cấp III. Bộ chỉ số này, được xem như là một công vụ có thể dùng để đánh giá hiện trạng cũng như hiệu quả của các hoạt động thích ứng với $\mathrm{BĐKH} \mathrm{và} \mathrm{thiên} \mathrm{tai} \mathrm{tại}$ các địa phương. Tuy nhiên, bộ chỉ số này chưa đưa ra được điểm số thích hợp bởi chưa xem xét tới độ ưu tiên trong bối cảnh của từng địa phương [10]. Trong khi đó, các mô hình kinh tế nông nghiệp, lâm nghiệp thích ứng với $\mathrm{BĐKH}$ tại ĐBSCL phần lớn ở cấp huyện và xã. Do vậy, nhằm đánh giá hiệu quả thực tế của các mô hình kinh tế thích ứng với biến đổi khí hậu tới cấp huyện và xã, nghiên cứu tiến hành xây dựng bộ chỉ số đánh giá về các phương diện như, đảm bảo tính hiệu quả về kinh tế, xã hội và bền vững đối với môi trường, khả năng thích ứng với biến đổi khí hậu, giảm nhẹ phát thải nhà kính dựa vào bối cảnh của từng địa phương Bởi mô hình kinh tế trước hết phải mang lại hiệu quả về kinh tế; có ý nghĩa tích cực và ghóp phần thúc đẩy sự phát triển của xã hội; phải đảm bảo môi trường, không đánh đổi môi trường lấy kinh tế; và phải có khả năng thích ứng với những biến đổi khí hậu trong tương lai gần và xa như lũ lụt, hạn hán, xâm nhập mặn. Từ đó, xây dựng cơ sở khoa học phục vụ cho việc đánh giá, triển khai, nhân rộng các mô hình và đề xuất các chính sách cho ứng phó $\mathrm{BĐKH} \mathrm{và} \mathrm{tăng}$ trưởng xanh trong vùng ĐBSCL.

\section{Phương pháp xây dụng bộ tiêu chí đánh giá hiệu quả mô hình kinh tế cấp huyện thích ứng với biến đổi khí hậu vùng ĐBSCL}

\subsection{Phương pháp kế thìa và tiếp cận hệ thống}

Khi nghiên cứu đề xuất bộ tiêu chí đánh giá hiệu quả mô hình kinh tế thích ứng với BĐKH cho vùng ĐBSCL, nhóm tác giả đã nghiên cứu một cách hệ thống về điều kiện tự nhiên, tài nguyên-môi trường và kế hoạch phát triển kinh tế-xã hội của vùng/tỉnh. Bên cạnh đó, các số liệu về điều kiện tự nhiên, tài nguyên môi trường, các tác động từ thiên nhiên và kinh tế xã hội từ nhóm các đề tài khoa học công nghệ, dự án do các ngành thực hiện, dự án hợp tác với nước ngoài cũng như các tài liệu về cơ sở pháp lý của quốc tế và Việt Nam đều được thu thập và phân tích để phục vụ cho việc đề xuất các nhóm chỉ tiêu đánh giá mô hình kinh tế thích ứng với BĐKH tại vùng ĐBSCL. 


\subsection{Phương pháp điều tra khảo sát và phỏng vấn thực địa}

Nghiên cứu này đã tiến hành điều tra khảo sát và phỏng vấn các hộ gia đình triển khai mô hình kinh tế thích ứng với BĐKH trên phạm vi 4 xã tại 3 huyện là xã Thuận An, thị xã Bình Minh, tỉnh Vĩnh Long, xã Bình Thạnh, thị xã Hồng Ngự, tỉnh Đồng Tháp, xã An Hòa Tây, huyện Ba Tri và xã An Điền, huyện Thạnh Phú, tỉnh Bến Tre thuộc vùng ĐBSCL. Đối tượng điều tra bao gồm các cán bộ quản lý, chuyên viên thuộc các cơ quan quản lý nhà nước. Cụ thể là Sở Tài nguyên và Môi trường tỉnh, Sở Nông nghiệp và Phát triển nông thôn tỉnh, phòng Kinh tế thị xã Bình Minh; Chi Cục Bảo vệ môi trường tỉnh, Văn phòng điều phối xây dựng nông thôn mới và tái cơ cấu ngành nông nghiệp tỉnh, Trung tâm Dịch vụ nông nghiệp thị xã, và UBND xã. Tại lần khảo sát thứ nhất, phương pháp này được thực hiện nhằm thu thập các báo cáo, thống kê tại vùng nghiên cứu về: Báo cáo thống kê, tổng hợp về tình hình phát triển kinh tế-xã hội hiện tại và quy hoạch phát triển kinh tế; Tốc độ phát triển kinh tế-xã hội của địa phương phục vụ cho xóa đói giảm nghèo và công nghiệp hóa, hiện đại hóa; Cơ cấu các ngành kinh tế công nghiệp, nông-ngư nghiệp, du lịch-dịch vụ; Các giải pháp thực hiện các mục tiêu phát triển kinh tế-xã hội; Cơ sở hạ tầng và tốc độ phát triển cơ sở hạ tầng; Đời sống vật chất và văn hóa tinh thần.

Tại lần khảo sát tiếp theo, cùng với việc thực hiện điều tra, khảo sát, nghiên cứu cũng thực hiện phỏng vấn thực địa: phỏng vấn, điều tra xã hội học áp dụng hình thức phỏng vấn trực tiếp 38 cán bộ của 3 tỉnh thí điểm triển khai mô hình kinh tế thích ứng biến đồi khí hậu; cán bộ lãnh đạo, quản lý cấp tỉnh/huyện là 10 người, cán bộ chuyên môn xã là 13 người; phỏng vấn, điều tra bằng phiếu gồm có 30 câu hỏi, chủ yếu là câu hỏi về những nội dung liên quan đến thích ứng với biến đổi khí hậu và mô hình kinh tế đang triển khai tại khu vực nghiên cứu; đồng thời cho phép thu thập các thông tin về nhân khẩu, sinh kế của người dân và các thông tin, đánh giá kinh tế xã hội cần thiết cho phân tích. Trong quá trình tiến hành điều tra, tác giả đã phát ra 60 phiếu và thu về 60 phiếu. Đối tượng được tham vấn bao gồm 52 nam và 8 nữ có độ tuổi từ 25 đến 71 tuổi, là những đối tượng trực tiếp tham gia triển khai các mô hình tại 4 xã được lựa chọn phỏng vấn.

\subsection{Phương pháp thảo luận nhóm tập trung (Focus Disscussion Group-FDG)}

Mục tiêu của phương pháp thảo luận nhóm tập trung thường được sử dụng để đánh giá các nhu cầu, các biện pháp can thiệp, thử nghiệm các ý tưởng hoặc chương trình mới, cải thiện chương trình hiện tại và thu thập các thông tin về một chủ đề nào đó phục vụ cho việc xây dựng bộ câu hỏi có cấu trúc [11-12].

Phương pháp FGD được áp dụng như là công cụ dùng để thu thập thông tin từ nhóm nghiên cứu và nhóm khảo sát thực địa về các mô hình kinh tế đang được áp dụng. Theo Morgan (1998), nhóm thành viên tham gia thảo luận theo phương pháp FGD sẽ bao gồm trung bình từ $8-10$ người. Do đó, nhóm nghiên cứu lựa chọn tổng cộng 8 thành viên tham gia thảo luận; mỗi nhóm có 4 người bao gồm các thành viên của nhóm khảo sát và nhóm chuyên môn nhằm tiến hành xem xét và thu hẹp phạm vi các tiêu chí đề xuất cho phù hợp với mục tiêu đề tài và bối cảnh nghiên cứu. Kết quả thảo luận nhóm đã xác định các điểm mạnh, điểm yếu, cơ hội và thách thức của các tiêu chí đánh giá mô hình kinh tế được lựa chọn [13].

\subsection{Phưong pháp chuyên gia Delphi}

Phương pháp chuyên gia Delphi chính là một quá trình thảo luận có bài bản để nhóm các chuyên gia tích lũy thông tin và thể hiện tri thức trong quá trình tham vấn nhằm đạt được sự đồng thuận về các vấn đề cụ thể [14]. Phương pháp Delphi thực hiện một quá trình tham vấn các bên liên quan, lặp đi, lặp lại phương pháp nghiên cứu định tính, mặt khác cũng sử dụng phương pháp nghiên cứu định lượng để mô tả mức độ đồng thuận về một số vấn đề cụ thể [15-20]. 
Phương pháp Delphi được ứng dụng để xác định các chỉ tiêu, chỉ số đánh giá hiệu quả của các mô hình kinh tế thích ứng với $\mathrm{BĐKH} \mathrm{hiện} \mathrm{đang} \mathrm{được} \mathrm{triển} \mathrm{khai} \mathrm{tại} \mathrm{ĐBSCL} \mathrm{thông} \mathrm{qua}$ quy trình 9 bước, trong 3 giai đoạn trước, trong và sau khi khi thực hiện tham vấn như sau:

Bước 1: Xây dựng kế hoạch chi tiết cho các bước thực hiện phương pháp chuyên gia Delphi.

Bước 2: Lựa chọn hội đồng chuyên gia tham vấn đảm bảo am hiểu vấn đề cần tham vấn. Số lượng các chuyên gia càng nhiều thì mức độ đạt được sự đồng thuận càng khó, nhưng sự đồng thuận sẽ mang tính chính xác cao hơn.

Bước 3: Xây dựng bộ câu hỏi Delphi theo các chỉ số và chỉ tiêu để đánh giá hiệu quả của các mô hình kinh tế thích ứng với $\mathrm{BĐKH.}$

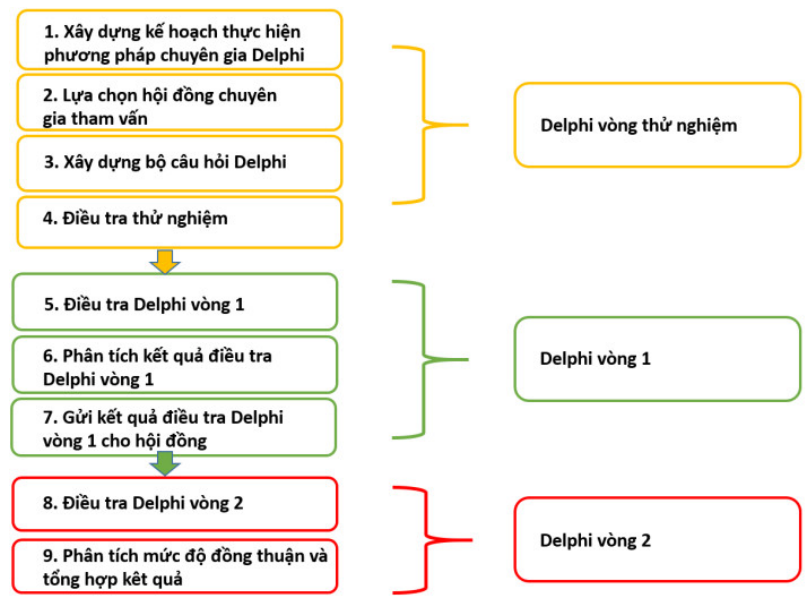

Hình 1. Quá trình lựa chọn các chỉ tiêu, chỉ số theo phương pháp Delphi [20].

Bước 4: Các bảng câu hỏi được thử nghiệm điều tra trong nhóm thực hiện.

Bước 5: Điều tra Delphi vòng 1 . Mức độ đồng thuận được sắp xếp từ 1-5 như sau: (1) rất không liên quan; (2) không liên quan; (3) có ít liên quan; (4) liên quan và (5) rất liên quan.

Bước 6: Phân tích kết quả điều tra Delphi vòng 1 dựa vào nguyên tắc KAMET đưa ra mức độ đánh giá quan trọng của mỗi chỉ số (qi) ở từng giai đoạn khác nhau trên cơ sở đánh giá tổ hợp các giá trị thống kê bao gồm Trung vị $\left(\mathrm{M}_{\mathrm{dqi}}\right)$; Độ lệch tứ phân vị $\left(\mathrm{Q}_{\mathrm{qi}}\right)$; Giá trị trung bình $\left(\mathrm{M}_{\mathrm{qi}}\right)$ và Phương sai $\left(\mathrm{V}_{\mathrm{qi}}\right.$ là tỷ lệ \% số chuyên gia thay đổi đánh giá) [15]. Quy tắc KAMET được miêu tả chi tiết trong Bảng 1.

Bảng 1. Quy tắc KAMET phân tích đánh giá từ các chuyên gia sử dụng phương pháp Delphi [15].

\begin{tabular}{|c|c|c|}
\hline Điều kiện & Vòng t cho câu hỏi Delphi & Vòng $t+1$ cho câu hỏi Delphi \\
\hline 1 & $\begin{array}{l}\text { Nếu } \mathrm{M}_{\mathrm{qi}} \geq 3,5 \text { và } \mathrm{Q}_{\mathrm{qi}} \leq 0,5 \text { và } \mathrm{V}_{\mathrm{qi}}< \\
15 \% \text { thì qi được chấp nhận và } \\
\text { không cần phải tham vấn về qi nữa }\end{array}$ & \\
\hline 2 & $\begin{array}{l}\text { Nếu } \mathrm{M}_{\mathrm{qi}} \geq 3,5 \text { và } \mathrm{V}_{\mathrm{qi}}>15 \% \text { thì thực } \\
\text { hiện vòng } 2\end{array}$ & $\begin{array}{l}\mathrm{M}_{\mathrm{qi}} \geq 3,5 \text { và } \mathrm{Q}_{\mathrm{qi}} \leq 0,5 \text { và } \mathrm{V}_{\mathrm{qi}}<15 \% \text { thì qi được } \\
\text { chấp nhận và không cần phải tham vấn về qi nữa }\end{array}$ \\
\hline 3 & $\begin{array}{l}\text { Nếu } \mathrm{M}_{\mathrm{qi}} \geq 3,5 \text { và } \mathrm{Q}_{\mathrm{qi}} \geq 75 \% \text { thì thực } \\
\text { hiện vòng } 2\end{array}$ & $\begin{array}{l}\mathrm{M}_{\mathrm{qi}} \geq 3,5 \text { và } \mathrm{Q}_{\mathrm{qi}} \leq 0,5 \text { và } \mathrm{V}_{\mathrm{qi}}<15 \% \text { thì qi được } \\
\text { chấp nhận và không cần phải tham vấn về qi nữa }\end{array}$ \\
\hline 4 & $\begin{array}{l}\text { Nếu } \mathrm{M}_{\mathrm{qi}}<3,5 \text { và } \mathrm{Q}_{\mathrm{qi}} \leq 0,5 \text { và } \mathrm{V}_{\mathrm{qi}} \leq \\
15 \% \text { thì qi bì loại và không cần phải } \\
\text { tham vấn về qi thêm nữa }\end{array}$ & \\
\hline
\end{tabular}

Ghi chú: Mqi: giá trị trung bình của các chỉ tiêu hay câu hỏi tham vấn (qi)

$Q_{q i}$ : độ lệch tứ phân vị

$V_{q i}$ : phuơng sai thể hiện tỷ lệ chuyên gia thay đổi ý kiến

Bước 7: Gửi kết quả điều tra Delphi cho hội đồng.

Bước 8: Điều tra Delphi vòng 2 tương tự như vòng 1.

Bước 9: Phân tích sự đồng thuận và tổng hợp kết quả. 


\section{Kết quả và thảo luận}

\subsection{Bộ tiêu chí đánh giá hiệu quả mô hình kinh tế cấp huyện thích úng với BĐKH vùng $Ð B S C L$}

Dựa trên danh sách cụ thể các nguồn tài liệu tham khảo đã chọn lọc và kế thừa để đề xuất các chỉ tiêu thành phần của bộ tiêu chí căn cứ theo mục tiêu cụ thể, phạm vi thực hiện và kết quả tham vấn tại vùng nghiên cứu của đề tài. Theo đó, nhóm chuyên môn và nhóm khảo sát đã xây dựng bộ tiêu chí đánh giá hiệu quả các mô hình kinh tế cấp huyện thích ứng với BĐKH vùng ĐBSCL bao gồm 36 chỉ tiêu và 49 chỉ tiêu thành phần. Sau đó, thực hiện phương pháp thảo luận nhóm tập trung nhằm thu hẹp phạm vi các tiêu chí đề xuất cho phù hợp và kết quả thảo luận được tóm tắt trong bảng 2 .

Bảng 2. Danh mục các buổi thảo luận nhóm tập trung và kết quả.

\begin{tabular}{|c|c|c|}
\hline $\begin{array}{c}\text { Buổi thảo } \\
\text { luận }\end{array}$ & Nội dung & Kết quả \\
\hline TL01 & $\begin{array}{l}\text { - Thảo luận về các nhóm tiêu } \\
\text { chí mục tiều của đề tài. } \\
\text { - Làm rõ các nhóm tiêu chí } \\
\text { chính cần tập trung nghiên cứu. }\end{array}$ & $\begin{array}{l}\text { - Xác định } 6 \text { nhóm tiêu chí mục tiêu của bộ tiêu chí mà đề tài } \\
\text { tập trung nghiên cứu. } \\
\text { - Xác định hai nhóm tiêu chí chính đặt trọng tâm trong bộ } \\
\text { tiêu chí là hiệu quả kinh tế và mục tiêu thích ứng với biến đồi } \\
\text { khí hậu. }\end{array}$ \\
\hline TL02 & $\begin{array}{l}\text { - Xem xét các chỉ tiêu thành } \\
\text { phần về tiêu chí hiệu quả kinh } \\
\text { tế - xã hội. }\end{array}$ & $\begin{array}{l}\text { - Bổ sung tiêu chí thành phần về khả năng thu hồi vốn của } \\
\text { mô hình triển khai. } \\
\text { - Loại bỏ tiêu chí đánh giá sự ổn định của mô hình trong quá } \\
\text { trình biến động của nền kinh tế. } \\
\text { - Gộp tiêu chí tăng/đa dạng hóa nguồn thu nhập và tạo việc } \\
\text { làm và tăng số lượng/đối tượng hưởng lợi thành một nội } \\
\text { dung. } \\
\text { - Gộp tiêu chí về sự tham gia của nhóm người khuyết tật và à } \\
\text { dân tộc thiểu số thành Thúc đẩy sự tham gia của các nhóm dế } \\
\text { bị tôn thương (đơn thân, người khuyết tật, dân tộc thiểu số, } \\
\text { v.v). }\end{array}$ \\
\hline TL03 & $\begin{array}{l}\text { - Xem xét các chỉ tiêu thành } \\
\text { phần về thích ứng với biến đổi } \\
\text { khí hậu, môi trường. }\end{array}$ & $\begin{array}{l}\text { - Tác động lên hệ sinh thái/đa dạng sinh học với TC thành } \\
\text { phần: Mô hình kinh tế này có ảnh hưởng đên hệ sinh thái/đa } \\
\text { dạng sinh học tự nhiên tại địa phương không: 1) tiêu cực } 2 \text { ) } \\
\text { trung bình } 3 \text { ) tích cực. } \\
\text { - Gộp } 3 \text { tiêu chí thành phần về khả năng thích ứng với } \\
\text { BĐKH hiện tại và thích ứng với BĐKH tương lai thành một } \\
\text { nội dung. } \\
\text { - Thay đổi mức đánh giá chỉ tiêu về khả năng thích ứng tốt } \\
\text { với tác động BĐKH tại địa phương thành thấp, trung bình và } \\
\text { cao. }\end{array}$ \\
\hline TL04 & $\begin{array}{l}\text { - Xem xét các chỉ tiêu thành } \\
\text { phần về tiêu chí hiệu quả kinh } \\
\text { tế và thể chế, chính sách. }\end{array}$ & $\begin{array}{l}\text { - Bổ sung tiêu chí thành phần về mức độ sẵn có của nguồn } \\
\text { vốn đầu tư (chi phí chuyển đồi sang mô hình thích ứng với } \\
\text { BĐKH). } \\
\text { - Bổ sung tiêu chí thành phần về khả năng tiếp cận vốn vay } \\
\text { của các hộ gia đình. } \\
\text { - Gộp tiếu chí về rào cản trong quy định và chính sách tài } \\
\text { chính đối với việc triển khai mô hình kinh tế. }\end{array}$ \\
\hline TL05 & $\begin{array}{l}\text { - Thảo luận về các nhóm tiêu } \\
\text { chí mục tiêu của đề tài. } \\
\text { - Thảo luận liên quan đến các } \\
\text { thông tin cần thu thập bồ sung } \\
\text { để xây dựng bộ tiêu chí dựa } \\
\text { trên các điều kiện, đặc điểm } \\
\text { của vùng nghiên cứu triển khai } \\
\text { các mô hình kinh tế thích ứng } \\
\text { với BĐKH. }\end{array}$ & $\begin{array}{l}\text { - Loại bỏ tiêu chí về mô hình kinh tế có thể thực hiện tại nhà } \\
\text { hay gần nhà. } \\
\text { - Loại bỏ tiêu chí về hộ nghèo trung bình, hộ nghèo không có } \\
\text { đất tham gia vào mô hình kinh tế. } \\
\text { - Loại bỏ tiêu chí về khả năng đầu tư và tiếp cận vốn vay của } \\
\text { hộ ít đất, hộ nghèo, hộ ít đất trung bình, và hộ cận nghèo. } \\
\text { - Xác định các thông tin cần thiết để nhóm khảo sát thực địa } \\
\text { tiếp tục thu thập. }\end{array}$ \\
\hline
\end{tabular}




\begin{tabular}{|c|c|c|}
\hline $\begin{array}{l}\text { Buổi thảo } \\
\text { luận }\end{array}$ & Nội dung & Kết quả \\
\hline TL06 & $\begin{array}{l}\text { - Tiếp tục thảo luận về chỉ tiêu } \\
\text { kinh tế. }\end{array}$ & $\begin{array}{l}\text { - Thay đổi mức đánh giá chỉ tiêu thành phần về năng suất khi } \\
\text { triển khai mô hình thành các mức }>25 \%, 25-50 \%, 51-70 \% \text {, } \\
71-100 \% \text { và }>100 \% \text {. } \\
\text { - Thay đồi mức đánh giá chỉ tiêu thành phần về chất lượng } \\
\text { sản phẩm đầu ra thành các mức }<50 \%, 51-75 \%, 76-100 \% \text { và } \\
>100 \% \text {. } \\
\text { - Thay đổi mức đánh giá chỉ tiêu thành phần về khả năng tiêu } \\
\text { thụ sản phẩm thành các mức đánh giá theo cấp độ: kém, thấp, } \\
\text { trung bình và cao. }\end{array}$ \\
\hline TL07 & $\begin{array}{l}\text { - Xem xét các chỉ tiêu thành } \\
\text { phần về thích ứng với biến đồi } \\
\text { khí hậu, bảo vệ môi trường và } \\
\text { quản lý - nhân rộng. }\end{array}$ & $\begin{array}{l}\text { - Thay đổi mức đánh giá chỉ tiêu thành phần về khả năng } \\
\text { thích ứng với BĐKH thành các mức không, trung bình và } \\
\text { cao. } \\
\text { - Thay đổi mức đánh giá chỉ tiêu thành phần về tận dụng cơ } \\
\text { hội có lợi do BĐKH đem lại thành các mức tăng, không thay } \\
\text { đồi và giảm. } \\
\text { - Thay đổi mức đánh giá chỉ tiêu thành phần về đánh giá } \\
\text { năng lực kỹ thuật thành các mức tăng sử dụng năng lượng, } \\
\text { không thay đổi và giảm sử dụng năng lượng. }\end{array}$ \\
\hline TL08 & $\begin{array}{l}\text { - Thảo luận về các tiêu chí } \\
\text { hiệu quả kinh tế - xã hội. }\end{array}$ & $\begin{array}{l}\text { - Thay đối mức đánh giá chỉ tiêu thành phần về mức độ rào } \\
\text { cản trong tiếp cận thị trường của mô hình thành cao, trung } \\
\text { bình, thấp và không có rào cản. } \\
\text { - Thay đồi mức đánh giá chỉ tiêu thành phần về mức độ sẵn } \\
\text { có của năng lực kỹ thuật để triển khai mô hình kinh tế thành } \\
\text { cao, trung bình và thấp. } \\
\text { - Đưa nội dung tiêu chí Kế thừa và phát huy kiến thức bản } \\
\text { địa vào mục Đánh giá năng lực kỹ thuật. } \\
\text { - Thay đồi mức đánh giá chỉ tiêu thành phần về rào cản trong } \\
\text { quy định, chính sách tài chính triển khai mô hình thành mức } \\
\text { nhiều - ít - không có. } \\
\text { - Loại bỏ tiêu chí về trở ngại thể chế đối với hộ nghèo khi } \\
\text { tham gia mô hình. }\end{array}$ \\
\hline TL09 & $\begin{array}{l}\text { - Tiếp tục thảo luận về các tiêu } \\
\text { chí thành phẩn theo sáu nhóm } \\
\text { chính. }\end{array}$ & $\begin{array}{l}\text { - Thay đổi mức đánh giá chỉ tiêu thành phần về sử dụng năng } \\
\text { lượng tái tạo thành các mức tăng, không và giảm lượng chất } \\
\text { thải ra môi trường đất và nước. } \\
\text { - Thay đồi mức đánh giá chỉ tiêu thành phần về mức độ sẵn } \\
\text { có của nguồn nguyên liệu trên phạm vi tỉnh thành không có, } \\
\text { đáp ứng được }<25 \%, 26-50 \%, 51-75 \% \text { hay } 76-100 \% \text {. } \\
\text { - Loại bỏ tiêu chí về các chi phí phát sinh (hạ tầng, thiêt bị, } \\
\text { vận chuyển, chi phí hoa hồng). } \\
\text { - Loại bỏ tiêu chí về trở ngại nào về văn hóa-xã hội đối với } \\
\text { hộ nghèo khi tham gia mô hình. }\end{array}$ \\
\hline TL10 & $\begin{array}{l}\text { - Thảo luận về các nhóm tiêu } \\
\text { chí mục tiêu của đề tài. }\end{array}$ & $\begin{array}{l}\text { - Chuyển nội dung tiêu chí thành phần từ đa dạng hóa sinh kế } \\
\text { của các hộ gia đình thành mô hình có tạo ra nhiều việc làm và } \\
\text { tăng đối tượng lao động hưởng lợi. } \\
\text { - Bồ sung phạm vi vùng vào tiêu chí thành phần về Quy mô } \\
\text { nhu cầu của thị trường đối với loại hình sản xuất. } \\
\text { - Thu hẹp còn } 25 \text { chỉ số thành phần tương ứng với } 6 \text { nhóm } \\
\text { tiêu chí chính. }\end{array}$ \\
\hline
\end{tabular}

Kết quả sau 10 buổi thảo luận nhóm tập trung, bộ tiêu chí được đề xuất với 6 nhóm tiêu chí chính và 25 chỉ số tương ứng với tổng điểm tối đa là 100 điểm; trong đó tiêu chí 1 về hiệu quả kinh tế chiếm $55 \%$ thể hiện là mục tiêu quan trọng nhất, và tiêu chí 4 thể hiện mục tiêu thích ứng với biến đổi khí hậu chiếm $16 \%$. Mỗi tiêu chí sẽ có các mức yêu cầu thông tin cụ thể khác nhau tương ứng với mô hình kinh tế áp dụng theo mức điểm số từ thấp đến cao. 


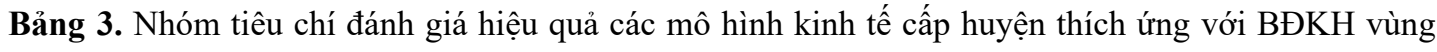
ĐBSCL.

\begin{tabular}{lcc}
\hline \multicolumn{1}{c}{ Tiêu chí chung } & Các chỉ số & Điểm \\
\hline Hiệu quả kinh tế - xã hội & & 64 \\
1. Kinh tế & 5 chỉ số & 55 \\
2. Thể chế, chính sách & 2 chỉ số & 6 \\
3. Văn hóa - xã hội & 3 chỉ số & 3 \\
\hline Biến đồi khí hậu và bảo vệ môi trương & & 26 \\
\hline 4. Thích ứng với BĐKH & 4 chỉ số & 16 \\
5. Bảo vệ môi trường & 6 chỉ số & 10 \\
Quản lý và nhân rộng & & 10 \\
6. Quản lý và nhân rộng & 5 chỉ số & 10 \\
Tống & & 100 \\
\hline
\end{tabular}

Bảng 4. Các tiêu chí đánh giá hiệu quả các mô hình kinh tế cấp huyện thích ứng với BĐKH vùng ĐBSCL.

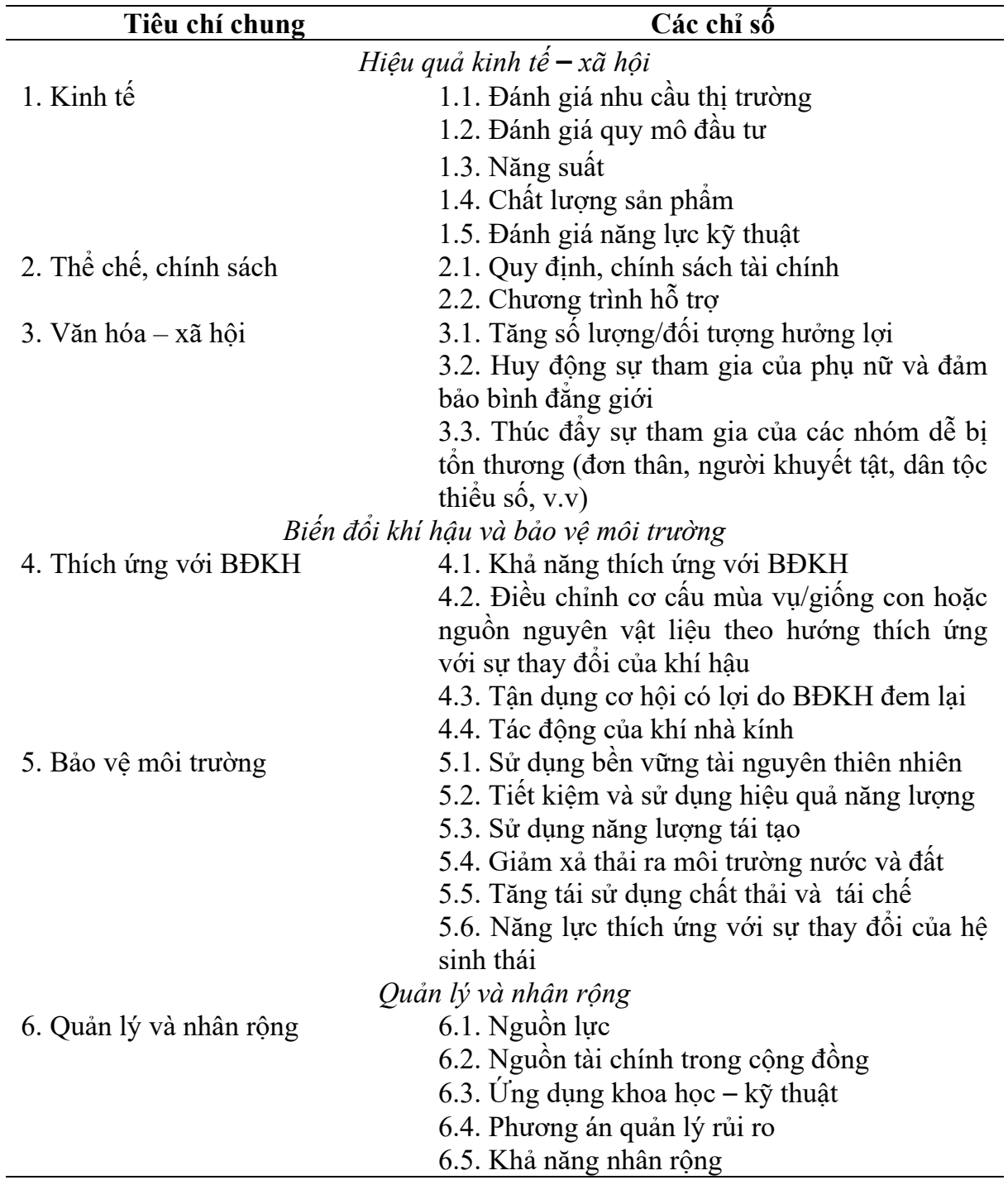

\section{2. Đánh giá sự phù hợp của bộ tiêu chí}

Bảng câu hỏi các tiêu chí, chỉ số đánh giá hiệu quả của các mô hình kinh tế thích ứng với biến đổi khí hậu tham khảo ý kiến chuyên gia bao gồm 6 nhóm tiêu chí chính và 35 chỉ số. Các chuyên gia được yêu cầu đánh giá mức độ đồng thuận với bộ chỉ số và chỉ tiêu đưa ra. 
Mức độ đồng thuận được sắp xếp từ 1-5 như sau: (1) rất không liên quan; (2) không liên quan; (3) có ít liên quan; (4) liên quan và (5) rất liên quan [15].

- Xác định chuyên gia tham vấn

Số lượng chuyên gia được lựa chọn để tham vấn trong áp dụng phương pháp Delphi là 15 chuyên gia, trong đó 5 chuyên gia trong lĩnh vực kinh tế, 4 chuyên gia lĩnh vực biến đổi khí hậu và môi trường, và 6 chuyên gia tới từ các tỉnh có mô hình thích ứng với $\mathrm{BĐKH} \mathrm{được}$ đánh giá. Các chuyên gia được lựa chọn có chuyên môn, kiến thức sâu rộng liên quan đến lĩnh vực biến đổi khí hậu, và các mô hình thích ứng với $\mathrm{BĐKH} \mathrm{tại} \mathrm{các} \mathrm{tỉnh.} \mathrm{Tên} \mathrm{các} \mathrm{chuyên} \mathrm{gia}$ được thay bằng mã theo nguyên tắc ẩn danh.

- Tham vấn chuyên gia

Các chuyên gia thực hiện đánh giá mức độ đồng thuận với bộ chỉ tiêu, chỉ số được đề xuất thông qua hai vòng tham vấn.

- Phân tích và đánh giá kết quả tham vấn chuyên gia

Kết quả tham vấn vòng 1 , không có chỉ tiêu hay chỉ số đánh giá hiệu quả của các mô hình kinh tế thích ứng với biến đồi khí hậu được đưa ra tham vấn nào bị loại. 27/35 tiêu chí, chỉ tiêu thỏa mãn điều kiện đầu tiên trong nguyên tắc KAMET (có giá trị trung bình $\geq 3,5$; Độ lệch trung vị $\leq 0,5$ và Phương sai $<15 \%$ [15]), có nghĩa là chúng đạt được sự đồng thuận cao từ các chuyên gia và được chấp nhận mà không cần phải tham vấn thêm. $8 / 35$ chỉ số chưa thực sự đạt được sự đồng thuận cao, cần phải tổ chức tham vấn thêm vòng 2 . Các chỉ số này chưa đạt được sự đồng thuận cao là do nguyên nhân chính: (1) nhiều chuyên gia lưỡng lự, thay đổi ý kiến dẫn đến phương sai có giá trị lớn từ $75 \%$ trở lên; và (2) mức điểm được chấm ở khoảng rộng, nên dẫn tới độ lệch phương vị lớn hơn $15 \%$.

Bảng 5. Kết quả đánh giá vòng 1 tham khảo ý kiến chuyên gia nhằm xây dựng bộ chỉ số.

\begin{tabular}{|c|c|c|c|c|c|c|}
\hline $\begin{array}{l}\text { Nhóm } \\
\text { chỉ số }\end{array}$ & Chỉ số & $\begin{array}{l}\text { Vòng } \\
\text { tham } \\
\text { vấn }\end{array}$ & $\begin{array}{l}\text { Kết quả } \\
\text { đánh giá } \\
\text { của các } \\
\text { chuyên gia }\end{array}$ & $\begin{array}{l}\text { Độ } \\
\text { lệch tứ } \\
\text { phân } \\
\text { vị }\end{array}$ & $\begin{array}{l}\text { Phương } \\
\text { sai (\%) }\end{array}$ & $\begin{array}{c}\text { Đánh } \\
\text { giá }\end{array}$ \\
\hline \multicolumn{7}{|l|}{ KT } \\
\hline KT1 & $\begin{array}{l}\text { Quy mô nhu cầu của thị trường đối với } \\
\text { loại hình sản xuất } \\
0: \text { Không } \\
\text { 1: Huyện/Tỉnh } \\
\text { 3: Vùng/Quốc gia } \\
\text { 5: Thế giới }\end{array}$ & Vòng 1 & 4,33 & 0,50 & 0 & $\begin{array}{l}\text { Chấp } \\
\text { nhận }\end{array}$ \\
\hline KT2 & $\begin{array}{l}\text { Mức đồ nắm bắt thị trường của các hộ gia } \\
\text { đình đổi với mô hình sản xuất này } \\
0 \text { : Không } \\
\text { 1: Thấp } \\
\text { 2: Trung bình } \\
\text { 3: Cao }\end{array}$ & Vòng 1 & 4,11 & 0,00 & 11 & $\begin{array}{l}\text { Chấp } \\
\text { nhận }\end{array}$ \\
\hline KT3 & $\begin{array}{l}\text { Rào cản trong quá trình tiếp cận thị trường } \\
\text { 1: Cao } \\
\text { 2: Thấp } \\
\text { 3: Trung bình } \\
\text { 4: Không có rào cản }\end{array}$ & Vòng 1 & 3,89 & 0,75 & 0 & Vòng 2 \\
\hline KT4 & $\begin{array}{l}\text { Mức độ sẵn có của nguồn nguyên vật liệu } \\
\text { đầu vào trên phạm vi cấp tỉnh } \\
\text { 1: Không có } \\
\text { 2: Đáp ứng được }<25 \% \\
\text { 3: Đáp ứng được } 26-50 \% \\
\text { 4: Đáá ứng được } 51-75 \% \\
\text { 5: Đáp ứng được } 76-100 \%\end{array}$ & Vòng 1 & 4,33 & 0,50 & 0 & $\begin{array}{l}\text { Chấp } \\
\text { nhận }\end{array}$ \\
\hline
\end{tabular}




\begin{tabular}{|c|c|c|c|c|c|c|}
\hline $\begin{array}{l}\text { Nhóm } \\
\text { chỉ số }\end{array}$ & Chỉ số & $\begin{array}{l}\text { Vòng } \\
\text { tham } \\
\text { vấn }\end{array}$ & $\begin{array}{l}\text { Kết quả } \\
\text { đánh giá } \\
\text { của các } \\
\text { chuyên gia }\end{array}$ & $\begin{array}{l}\text { Độ } \\
\text { lệch tứ } \\
\text { phân } \\
\text { vị }\end{array}$ & $\begin{array}{l}\text { Phương } \\
\text { sai (\%) }\end{array}$ & $\begin{array}{l}\text { Đánh } \\
\text { giá }\end{array}$ \\
\hline KT5 & $\begin{array}{l}\text { Mức độ sẵn có của nguồn vốn đầu tư (chi } \\
\text { phí chuyển đổi sang mô hình thích ứng với } \\
\text { BĐKH) } \\
2:<50 \% \text { nguồn vốn sẵn có } \\
4: 51-75 \% \text { nguồn vốn } \\
\text { 6: } 76-100 \% \text { nguồn vốn }\end{array}$ & Vòng 1 & 4,22 & 0,50 & 0 & $\begin{array}{l}\text { Chấp } \\
\text { nhận }\end{array}$ \\
\hline KT6 & $\begin{array}{l}\text { Khả năng tiếp cận vốn vay của các hộ gia } \\
\text { đình } \\
0: \text { Không có } \\
\text { 1: Tiếp cận ít } \\
\text { 2: Tiếp cận trung bình } \\
\text { 3: Tiếp cận cao }\end{array}$ & Vòng 1 & 4,33 & 0,50 & 0 & $\begin{array}{l}\text { Chấp } \\
\text { nhận }\end{array}$ \\
\hline KT7 & $\begin{array}{l}\text { Khả năng thu hồi vốn của mô hình khi } \\
\text { triền khai } \\
\text { 2: > } 5 \text { năm } \\
\text { 4: } 3-5 \text { năm } \\
\text { 6: } 1-3 \text { năm }\end{array}$ & Vòng 1 & 4,44 & 0,50 & 11 & $\begin{array}{l}\text { Chấp } \\
\text { nhận }\end{array}$ \\
\hline KT8 & $\begin{array}{l}\text { Mức độ sẵn có của các hạ tầng thiết yếu } \\
\text { phục vụ mô hình sản xuất } \\
0: \text { Không } \\
\text { 1: Có }\end{array}$ & Vòng 1 & 4,44 & 0,50 & 22 & Vòng 2 \\
\hline KT9 & $\begin{array}{l}\text { Năng suất của việc triển khai mô hình có } \\
\text { đạt như kỳ vọng } \\
0:>25 \% \\
1: 25-50 \% \\
3: 51-70 \% \\
5: 71-100 \% \\
7:>100 \%\end{array}$ & Vòng 1 & 4,11 & 0,25 & 0 & $\begin{array}{l}\text { Chấp } \\
\text { nhận }\end{array}$ \\
\hline KT10 & $\begin{array}{l}\text { Chât lượng sản phẩm đầu ra có đạt yêu cầu } \\
0:<50 \% \\
2: 51-75 \% \\
4: 76-100 \% \\
6:>100 \%\end{array}$ & Vòng 1 & 4,11 & 0,75 & 0 & Vòng 2 \\
\hline KT11 & $\begin{array}{l}\text { Khả năng tiêu thụ sản phẩm như mong } \\
\text { muốn } \\
0: \text { Kém } \\
\text { 2: Thấp } \\
\text { 4: Trung bình } \\
\text { 6: Cao }\end{array}$ & Vòng 1 & 4,22 & 0,75 & 11 & Vòng 2 \\
\hline KT12 & $\begin{array}{l}\text { Mức độ sẵn có của năng lực kỹ thuật để } \\
\text { triển khai mô hình kinh tế (kết hợp kiến } \\
\text { thức bản địa và kiến thức khoa học) } \\
0 \text { : Thấp } \\
\text { 1: Trung bình } \\
\text { 2: Cao }\end{array}$ & Vòng 1 & 4,22 & 0,50 & 0 & $\begin{array}{l}\text { Chấp } \\
\text { nhận }\end{array}$ \\
\hline KT13 & $\begin{array}{l}\text { Khả năng đào tạo, nâng cao năng lực cần } \\
\text { thiết } \\
0 \text { : Không } \\
1 \text { : Có }\end{array}$ & Vòng 1 & 4,22 & 0,50 & 0 & $\begin{array}{l}\text { Chấp } \\
\text { nhận }\end{array}$ \\
\hline $\begin{array}{c}\text { TC } \\
\text { TC1 }\end{array}$ & $\begin{array}{l}\text { Rào cản về quy định đối với việc triển khai } \\
\text { mô hình kinh tế: } \\
\text { Giấy phép triền khai } \\
\text { Quy định an toàn kỹ thuật } \\
\text { Quy định môi trường } \\
\text { Chứng nhận sản phầm }\end{array}$ & Vòng 1 & 4,11 & 0,75 & 0 & Vòng 2 \\
\hline
\end{tabular}




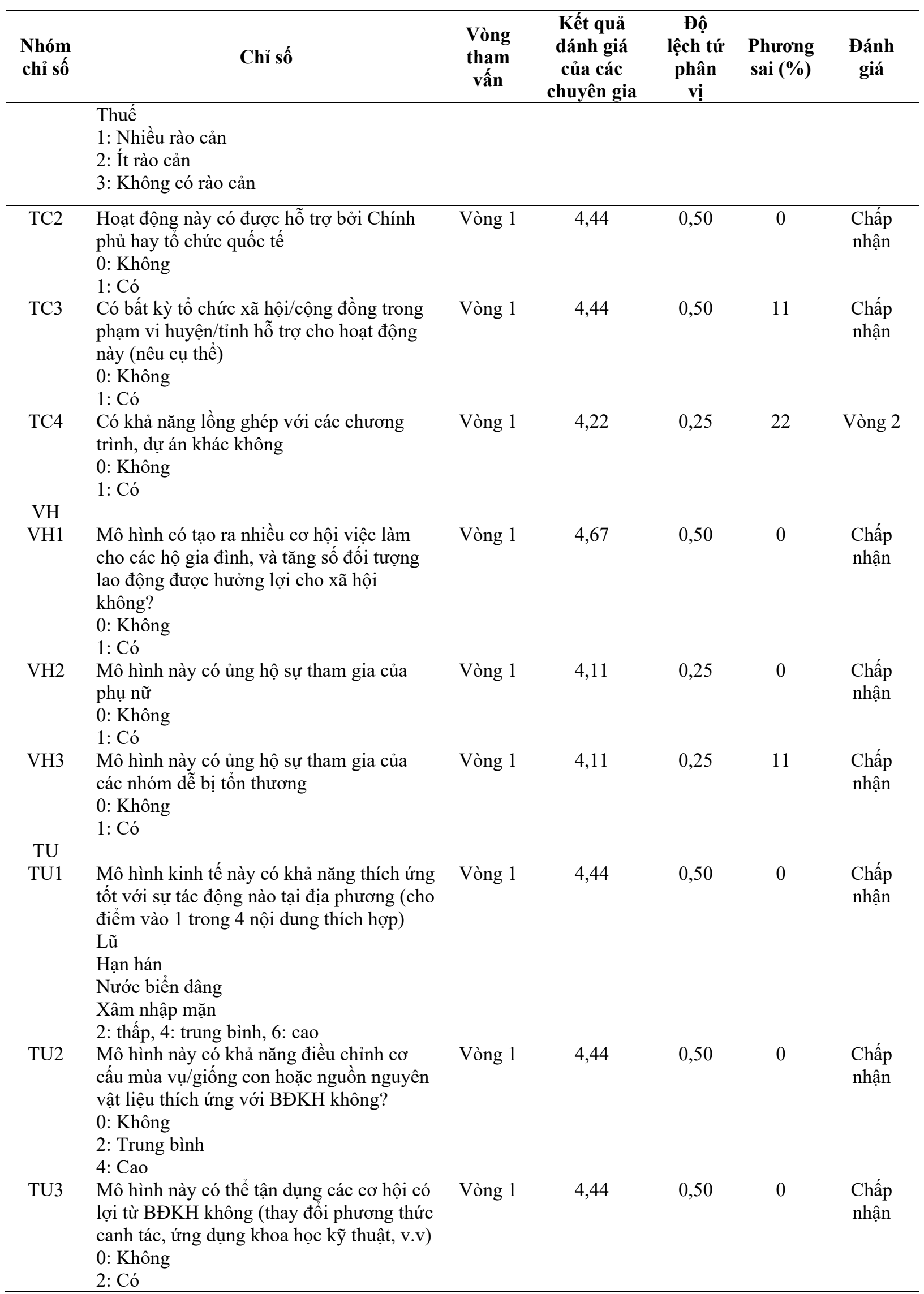




\begin{tabular}{|c|c|c|c|c|c|c|}
\hline $\begin{array}{l}\text { Nhóm } \\
\text { chỉ số }\end{array}$ & Chỉ số & $\begin{array}{l}\text { Vòng } \\
\text { tham } \\
\text { vấn }\end{array}$ & $\begin{array}{l}\text { Kết quả } \\
\text { đánh giá } \\
\text { của các } \\
\text { chuyên gia }\end{array}$ & $\begin{array}{l}\text { Độ } \\
\text { lệch tứ } \\
\text { phân } \\
\text { vị }\end{array}$ & $\begin{array}{l}\text { Phương } \\
\text { sai (\%) }\end{array}$ & $\begin{array}{l}\text { Đánh } \\
\text { giá }\end{array}$ \\
\hline TU4 & $\begin{array}{l}\text { Mô hình kinh tế này có giảm lượng khí } \\
\text { thải nhà kính vào khí quyê̂n không } \\
0 \text { : Tăng } \\
\text { 2: Không thay đổi } \\
\text { 4: Giảm }\end{array}$ & Vòng 1 & 4,44 & 0,50 & 0 & $\begin{array}{l}\text { Chấp } \\
\text { nhận }\end{array}$ \\
\hline \multicolumn{7}{|c|}{ 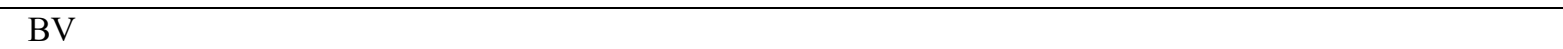 } \\
\hline BV1 & $\begin{array}{l}\text { Mức độ tương thích của mô hình với việc } \\
\text { sử dụng bền vững tài nguyên thiên nhiên } \\
\text { của địa phương } \\
\text { 1: Thấp } \\
\text { 2: Trung bình } \\
\text { 3: Cao }\end{array}$ & Vòng 1 & 4,33 & 0,50 & 11 & $\begin{array}{l}\text { Chấp } \\
\text { nhận }\end{array}$ \\
\hline BV2 & $\begin{array}{l}\text { Mô hình này có hướng đến tiết kiệm và sử } \\
\text { dụng hiệu quả nguồn năng lượng hiện có } \\
\text { không/có giảm mức năng lượng sử dụng? } \\
\text { 0: Tăng sử dụng năng lượng } \\
\text { 1: Không thay đổi } \\
\text { 2: Giảm sử dụng năng lượng }\end{array}$ & Vòng 1 & 4,22 & 0,50 & 22 & Vòng 2 \\
\hline BV3 & $\begin{array}{l}\text { Mô hình này có tăng sử dụng nguồn năng } \\
\text { lượng tái tạo không } \\
0 \text { : Không } \\
\text { 1: Có }\end{array}$ & Vòng 1 & 4,22 & 0,75 & 0 & Vòng 2 \\
\hline BV4 & $\begin{array}{l}\text { Mô hình này có giảm thiểu lượng chất thải } \\
\text { ra môi trường đât và nước không } \\
0 \text { : Tăng } \\
\text { 1: Không } \\
\text { 2: Giảm }\end{array}$ & Vòng 1 & 4,00 & 0,00 & 0 & $\begin{array}{l}\text { Chấp } \\
\text { nhận }\end{array}$ \\
\hline BV5 & $\begin{array}{l}\text { Mô hình này có tăng khả năng tái sử dụng } \\
\text { chất thải và tái chế không } \\
0 \text { : Không } \\
1 \text { : Có }\end{array}$ & Vòng 1 & 4,00 & 0,00 & 11 & $\begin{array}{l}\text { Chấp } \\
\text { nhận }\end{array}$ \\
\hline BV6 & $\begin{array}{l}\text { Mô hình có đủ linh hoạt để phù hợp với } \\
\text { những thay đổi của hệ sinh thái hiện nay } \\
\text { (thay đổi các loài sâu hại mới, giông cây } \\
\text { trồng/vật nuôi, v.v)? } \\
\text { 0: Không } \\
\text { 1: Có }\end{array}$ & Vòng 1 & 4,56 & 0,50 & 0 & $\begin{array}{l}\text { Chấp } \\
\text { nhận }\end{array}$ \\
\hline \multicolumn{7}{|c|}{ 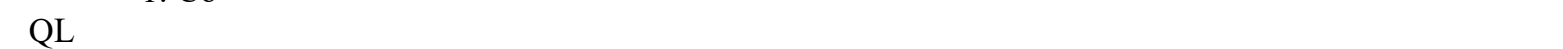 } \\
\hline QL1 & $\begin{array}{l}\text { Huy động được các nguồn lực để thực hiện } \\
0: \text { Không } \\
\text { 1: Có }\end{array}$ & Vòng 1 & 4,67 & 0,50 & 0 & $\begin{array}{l}\text { Chấp } \\
\text { nhận }\end{array}$ \\
\hline QL2 & $\begin{array}{l}\text { Có nguồn tài chính vi mô trong cộng } \\
\text { đồng/Quỹ tín dụng cộng đồng } \\
0: \text { Không } \\
1 \text { : Có }\end{array}$ & Vòng 1 & 4,44 & 0,50 & 0 & $\begin{array}{l}\text { Chấp } \\
\text { nhận }\end{array}$ \\
\hline QL3 & $\begin{array}{l}\text { Quy trình thực hiện và ứng dụng khoa học } \\
\text { - kỹ thuật đơn giản và dễ áp dụng } \\
0 \text { : Không } \\
\text { 3: Có }\end{array}$ & Vòng 1 & 4,22 & 0,25 & 0 & $\begin{array}{l}\text { Chấp } \\
\text { nhận }\end{array}$ \\
\hline QL4 & $\begin{array}{l}\text { Có lường trước rủi ro, thách thức tiềm tàng } \\
\text { và có phương án quản lý rủi ro (rủi ro khí } \\
\text { hậu, chính sách, nguồn lực hoặc thị } \\
\text { trường, v.v) không? } \\
\text { 0: Không } \\
\text { 2: Có }\end{array}$ & Vòng 1 & 4,33 & 0,50 & 11 & $\begin{array}{l}\text { Chấp } \\
\text { nhận }\end{array}$ \\
\hline
\end{tabular}




\begin{tabular}{llccccc}
\hline $\begin{array}{c}\text { Nhóm } \\
\text { chỉ số }\end{array}$ & \multicolumn{1}{c}{ Chỉ số } & $\begin{array}{c}\text { Vòng } \\
\text { tham } \\
\text { vấn }\end{array}$ & $\begin{array}{c}\text { Kết quả } \\
\text { đánh giá } \\
\text { của các } \\
\text { chuyên gia }\end{array}$ & $\begin{array}{c}\text { Độ } \\
\text { lệch tứ } \\
\text { phân } \\
\text { vị }\end{array}$ & $\begin{array}{c}\text { Phương } \\
\text { sai (\%) }\end{array}$ & $\begin{array}{c}\text { Đánh } \\
\text { giá }\end{array}$ \\
\hline QL5 & $\begin{array}{l}\text { Có khả năng nhân rộng ra các địa phương } \\
\text { với điều kiện tương tự } \\
\text { 0: Không } \\
\text { 3: Có }\end{array}$ & Vòng 1 & 4,11 & 0,25 & 0 & $\begin{array}{c}\text { Chấp } \\
\text { nhận }\end{array}$ \\
& & & & & \\
\hline
\end{tabular}

Tại vòng tham vấn thứ hai, $8 / 35$ chỉ tiêu, chỉ số này chưa đạt được sự đồng thuận ở vòng 1 đã thỏa mãn điều kiện đầu tiên trong nguyên tắc KAMET [15], đạt được sự đồng thuận từ các chuyên gia, hay được chấp nhận mà không cần phải tham vấn thêm vòng 3 .

Bảng 6. Kết quả đánh giá vòng 2 (dành cho 8 chỉ tiêu).

\begin{tabular}{|c|c|c|c|c|c|c|}
\hline $\begin{array}{l}\text { Nhóm } \\
\text { chỉ số }\end{array}$ & Chỉ số & $\begin{array}{l}\text { Vòng } \\
\text { tham } \\
\text { vấn }\end{array}$ & $\begin{array}{l}\text { Kết quả } \\
\text { đánh giá } \\
\text { của các } \\
\text { chuyên gia }\end{array}$ & $\begin{array}{l}\text { Độ } \\
\text { lệch tứ } \\
\text { phân } \\
\text { vị }\end{array}$ & $\begin{array}{l}\text { Phương } \\
\text { sai (\%) }\end{array}$ & $\begin{array}{c}\text { Đánh } \\
\text { giá }\end{array}$ \\
\hline \multicolumn{7}{|l|}{ KT } \\
\hline KT3 & $\begin{array}{l}\text { Rào cản trong quá trình tiếp cận thị trường } \\
\text { 1: Cao } \\
\text { 2: Thấp } \\
\text { 3: Trung bình } \\
\text { 4: Không có rào cản }\end{array}$ & Vòng 2 & 4,11 & 0,25 & 0 & $\begin{array}{l}\text { Chấp } \\
\text { nhận }\end{array}$ \\
\hline KT8 & $\begin{array}{l}\text { Mức độ sẵn có của các hạ tầng thiết yếu } \\
\text { phục vụ mô hình sản xuât } \\
0: \text { Không } \\
1 \text { : Có }\end{array}$ & Vòng 2 & 4,44 & 0,50 & 0 & $\begin{array}{l}\text { Chấp } \\
\text { nhận }\end{array}$ \\
\hline KT10 & $\begin{array}{l}\text { Chât lượng sản phẩm đầu ra có đạt yêu cầu } \\
0:<50 \% \\
2: 51-75 \% \\
4: 76-100 \% \\
6:>100 \%\end{array}$ & Vòng 2 & 4,22 & 0,50 & 0 & $\begin{array}{l}\text { Chấp } \\
\text { nhận }\end{array}$ \\
\hline KT11 & $\begin{array}{l}\text { Khả năng tiêu thụ sản phẩm như mong } \\
\text { muốn } \\
0: \text { Kém } \\
\text { 2: Thấp } \\
\text { 4: Trung bình } \\
\text { 6: Cao }\end{array}$ & Vòng 2 & 4,33 & 0,50 & 0 & $\begin{array}{l}\text { Chấp } \\
\text { nhận }\end{array}$ \\
\hline \multicolumn{7}{|c|}{ S } \\
\hline TC1 & $\begin{array}{l}\text { Rào cản về quy định đối với việc triển khai } \\
\text { mô hình kinh tế: } \\
\text { Giấy phép triển khai } \\
\text { Quy định an toàn kỹ thuật } \\
\text { Quy định môi trường } \\
\text { Chứng nhận sản phẩm } \\
\text { Thuế } \\
\text { 1: Nhiều rào cản } \\
\text { 2: Ít rào cản } \\
\text { 3: Không có rào cản }\end{array}$ & Vòng 2 & 4,22 & 0,50 & 0 & $\begin{array}{l}\text { Chấp } \\
\text { nhận }\end{array}$ \\
\hline TC4 & $\begin{array}{l}\text { Có khả năng lồng ghép với các chương } \\
\text { trình, dự án khác không } \\
0: \text { Không } \\
\text { 1: Có }\end{array}$ & Vòng 2 & 4,22 & 0,25 & 0 & $\begin{array}{l}\text { Chấp } \\
\text { nhận }\end{array}$ \\
\hline $\begin{array}{c}\text { BV } \\
\text { BV2 }\end{array}$ & $\begin{array}{l}\text { Mô hình này có hướng đến tiết kiệm và sử } \\
\text { dụng hiệu quả nguồn năng lượng hiện có } \\
\text { không/có giảm mức năng lượng sử dụng? } \\
\text { 0: Tăng sử dụng năng lượng } \\
\text { 1: Không thay đổi }\end{array}$ & Vòng 2 & 4,22 & 0,50 & 0 & $\begin{array}{l}\text { Chấp } \\
\text { nhận }\end{array}$ \\
\hline
\end{tabular}




\begin{tabular}{|c|c|c|c|c|c|c|}
\hline $\begin{array}{l}\text { Nhóm } \\
\text { chỉ số }\end{array}$ & Chỉ số & $\begin{array}{l}\text { Vòng } \\
\text { tham } \\
\text { vấn }\end{array}$ & $\begin{array}{l}\text { Kết quả } \\
\text { đánh giá } \\
\text { của các } \\
\text { chuyên gia }\end{array}$ & $\begin{array}{l}\text { Độ } \\
\text { lệch tứ } \\
\text { phân } \\
\text { vị }\end{array}$ & $\begin{array}{l}\text { Phương } \\
\text { sai (\%) }\end{array}$ & $\begin{array}{c}\text { Đánh } \\
\text { giá }\end{array}$ \\
\hline & 2: Giảm sử dụng năng lượng & & & & & \\
\hline BV3 & $\begin{array}{l}\text { Mô hình này có tăng sử dụng nguồn năng } \\
\text { lượng tái tạo không } \\
0 \text { : Không } \\
1 \text { : Có }\end{array}$ & Vòng 2 & 4,44 & 0,50 & 0 & $\begin{array}{l}\text { Chấp } \\
\text { nhận }\end{array}$ \\
\hline
\end{tabular}

Như vậy, sau 2 vòng tham vấn ý kiến chuyên gia, 35 chỉ tiêu thuộc 6 tiêu chí đánh giá hiệu quả của các mô hình kinh tế thích ứng với $\mathrm{BĐKH} \mathrm{đã} \mathrm{đạt} \mathrm{được} \mathrm{sự} \mathrm{chấp} \mathrm{thuận} \mathrm{và} \mathrm{đồng}$ thuận từ quan điểm của các chuyên gia. Bộ chỉ tiêu, chỉ số này hoàn toàn có đủ độ tin cậy để thực hiện đánh giá hiệu quả của các mô hình kinh tế thích ứng với BĐKH trong vùng ĐBSCL.

\section{Kết luận}

Xây dựng bộ tiêu chí đánh giá tính hiệu quả của các mô hình kinh tế cho vùng ĐBSCL có ý nghĩa nhằm đánh giá tính hiệu quả các mô hình kinh tế thích ứng triển khai tại các địa phương; xác định xem một mô hình sinh kế có phải là thích ứng với $\mathrm{BĐKH} \mathrm{hay} \mathrm{không} \mathrm{hay}$ chỉ là các mô hình can thiệp sinh kế thông thường khác; và là cơ sở hỗ trợ cho việc giám sát và đánh giá tính hiệu quả kinh tế và khả năng thích ứng của mô hình. Nghiên cứu đã tiến hành xây dựng được bộ tiêu chí gồm 6 nhóm tiêu chí chính và 25 chỉ số tương ứng nhằm đánh giá hiệu quả của các mô hình kinh tế thích ứng với $\mathrm{BĐKH} \mathrm{về} \mathrm{các} \mathrm{phương} \mathrm{diện} \mathrm{như,} \mathrm{khả} \mathrm{năng}$ thích ứng với biến đổi khí hậu, giảm nhẹ phát thải nhà kính và đảm bảo tính hiệu quả và bền vững đối với môi trường, kinh tế và xã hội. Trong 6 nhóm tiêu chí, tiêu chí về hiệu quả kinh tế và tiêu chí về mục tiêu thích ứng với $B Đ K H$ là những mục tiêu quan trọng nhất.

Để xây dựng một bộ tiêu chí đánh giá được các mô hình kinh tế thích ứng với BĐKH ở quy mô cấp huyện và xã, nhất thiết cần phải được thiết lập và xem xét một cách tổng thể, toàn diện bối cảnh cụ thể của địa phương dựa trên cơ sở tham khảo và kế thừa các nghiên cứu trước đây của các cơ quan, tổ chức trong và ngoài nước về các tiêu chí đánh giá hiệu quả mô hình kinh tế thích ứng với $\mathrm{BĐKH}$ trên phạm vi cấp huyện; đồng thời kết hợp phương pháp FDG với các buổi thảo luận nhóm tập trung và phương pháp Delphi gồm các chuyên gia có chuyên môn sâu và kinh nghiệm về lĩnh vực nghiên cứu. Trong tương lai, các tiêu chí này sẽ là cơ sở thực tiễn quan trọng cho các nhà hoạch định chính sách cũng như người dân trong việc ra quyết định về đầu tư triển khai, nhân rộng mô hình phù hợp và đạt hiệu quả cao.

Đóng góp của tác giả: Xây dựng ý tưởng nghiên cứu: Đ.N.Đ., N.V.T., L.N.C.; Lựa chọn phương pháp nghiên cứu: Đ.N.Đ., N.V.T., L.N.C., L.V.Q., P.T.Q.; Xử lý số liệu: Đ.N.Đ., L.N.C., L.V.Q., P.T.Q.; Viết bản thảo bài báo: Đ.N.Đ., N.V.T., L.N.C., L.V.Q., P.T.Q.; Chỉnh sửa bài báo: Đ.N.Đ., N.V.T., L.N.C., L.V.Q., P.T.Q., P.V.S.

Lời cảm ơn: Nhóm nghiên cứu xin chân thành cảm ơn sự hỗ trợ của đề tài khoa học "Nghiên cứu cơ sở khoa học xây dựng bộ tiêu chí đánh giá hiệu quả các mô hình kinh tế cấp huyện thích ứng với biến đổi khí hậu vùng đồng bằng sông Cửu Long, thí điểm tại một huyện điển hình", mã số: TNMT.2017.05.22 trong việc thực hiện và công bố nghiên cứu này.

Lời cam đoan: Tập thể tác giả cam đoan bài báo này là công trình nghiên cứu của tập thể tác giả, chưa được công bố ở đâu, không được sao chép từ những nghiên cứu trước đây; không có sự tranh chấp lợi ích trong nhóm tác giả.

\section{Tài liệu tham khảo}

1. Mackey, P.; Russell, M. Socialist republic of Vietnam: climate change impact and adaptation study in the Mekong Delta, Technical assistance consultant's final report, ADB, 2011. 
2. Tuan, L.A.; Chinawanno, S. Climate change in the Mekong river delta and key concerns on future climate threats in a book "Environmental change and agricultural sustainability in the Mekong Delta. Adv. Global Res. 2011, 207-217.

3. Tam, H.T.; Shimada, K. The effects of climate smart agriculture and climate change adaptation on the technical efficiency of rice farming-an empirical study in the Mekong delta of Vietnam. J. Agric. 2019, 9, 99.

4. Tuan, L.A. Some activities cope with climate change in Mekong Delta. The project: Capacity building on climate change for some civil organizations in Vietnam. Cantho, 2011.

5. Phu, V.L. Community-based adaptation to climate change: a case of Soc Trang, Vietnam. J. Resour. Environ. 2018, 8, 155-163.

6. Duc. D.H. Sustainability of the rice-shrimp farming system in Mekong Delta, Vietnam: a climate adaptive model. J. Econ. Dev. 2020, 22.

7. Gam, N.H. Transformation of Mekong Delta economic growth model adaptation to climate change: the situation and solutions. VNU J. Sci.: Policy Manage. Stud. 2019, 35, 84-95.

8. Linh, N.T.M. Assessing effectiveness of the models of large-scale rice field and traditional rice cultivation in Nga Nam district, Soc Trang province. Can Tho Uni. J. Sci.: Environ. Clim. Change 2017, 15, 45-54.

9. CARE VietNam. Action Research on Climate Resilient Livelihoods for Land poor and Landless People Vietnamese, 2015.

10. Huong, H.T. L. Development of adaptation indicators sets for efficiency of adaptation actions to serve the state management of climate change activities. Viet Nam Institute of Meteorology, Hydrology and Climate change (IMHEN), 2015.

11. Czarniawska, B. Narratives in Social Science Research, Sage Publications, London, 2004; pp. 141.

12. Stewart, D.W; Shamdasani, P.N. Focus Groups-Theory and Practice, Sage Publications, London, 1990; pp. 188.

13. Morgan, D.L. The Focus Group Guidebook-FG Kit 1, Sage Publications, London, 1998; pp. 103.

14. Linstone, H.A.; Turoff, M.; Helmer, O. The Delphi method, techniques và application. Murray Turoff and Harold A. Linstone, USA, 2002; pp. 621.

15. Chu, H.C.; Hwang, G.J. A Delphi - based approach to developing expert systems wtih the cooperation of multiple experts. Expert Syst. Appl. 2008, 34, 2826-2840.

16. Bunting, S. Horixontally integrated aquaculture development: Exploring concesus on constraints và oppotunities with a stakeholder Delphi. Aquacult. Int. 2008, 16, 153146.

17. Seyyed, A.D. An investigation of key competitiveness indicators và drivers of fullservice airlines using Delphi và AHP techiques. J. Air Transp. Manage. 2016, 52, 23-34.

18. Thịnh, N.A. Hội nhập vùng trong bảo vệ môi trường, phòng tránh thiên tai và ứng phó biến đổi khí hậu: bối cảnh cộng đồng GMS-ASEAN và triển vọng đối với vùng liên kết Tây Nguyên-duyên hải Nam Trung Bộ. Hội nghị Khoa học Địa lý toàn quốc lần thứ 8, TP. Hồ Chí Minh, 2014, pp. 700-711.

19. Hải, L.T.; Hải, P.H.; Khoa, N.T.; Hens. L. Các chỉ số cho phát triển bền vững: Lấy ví dụ nghiên cứu điểm tỉnh Quảng Trị, Việt Nam. Kỷ yếu hội thảo quốc tế Việt Nam học lần thứ ba: Tài nguyên thiên nhiên, môi trường và phát triển bền vững, 2015.

20. Hương, C.T.T. Nghiên cứu cơ sở khoa học trong việc đánh giá các giải pháp thích ứng với biến đổi khí hậu, áp dụng cho tỉnh Quảng Ngãi. Luận án tiến sĩ, 2018. 


\title{
Designing criteria for assessing the efficiency of district-level climate change adaptation economic models in Mekong Delta
}

\author{
Dang Ngoc Diep ${ }^{*}$, Nguyen Van Thang², Le Ngoc Cau², Le Van Quy², Pham Thi Quynh², \\ Pham Van $S y^{2}$ \\ ${ }^{1}$ Ministry of Natural Resource and Environment; diepvp.ttcp@gmail.com \\ ${ }^{2}$ Vietnam Institute of Metorology, Hydrology and Climate change; \\ nvthang.62@gmail.com; caukttv@gmail.com; vanquymt@gmail.com; \\ quynhpt0310@gmail.com; phamsymt@gmail.com
}

\begin{abstract}
The Mekong Delta has suffered great impacts from climate change such as sea level rise, saltwater intrusion, erosion and flooding, which bring a great threat to agricultural development, national food security and cause great damage to regional socio-economic development. In recent years, many new district-level economic models have been formed and deployed in a number of areas of the Mekong Delta, such as Rice-Fish system model, Elephant grass model to raise cows and goats, and gradually bring certain economic benefits. The implementation and replication of economic models could be deployed in other regions through the in-depth assessments of economic efficiency and climate change adaptation. Currently, there are separate sets of criteria for evaluating economic efficiency, or effectiveness of climate change adaptation. However, there is no set of criteria for evaluating both economic and climate change adaptation at district and commune scales. Therefore, this study was conducted to develop a set of criteria to evaluate the efficiency of climate change adaptation economic models. The approaches employed were inheritance method, systematic analysis, focus discussion group, Delphi and expert, officials, household interviews. The set of criteria is proposed with 6 main groups of criteria and 25 corresponding indicators in terms of climate change adaptation, greenhouse gas emission reduction and ensuring efficiency and sustainability to the environment, economy and society.
\end{abstract}

Keywords: Set of criteria; Economic models; Climate change adaptation. 